\title{
The Value of Aspiration Cytology in Cystic Lesions of the Maxillofacial Region
}

Timucin Baykula

Gulumser Colok

Omer Gunhanc

\section{ABSTRACT}

Objectives: The majority of the pathologic structures which are seen in the oral and maxillofacial region are either cystic or tend to show cystic changes. They may have not specific clinical and radiographic findings. Therefore, it is difficult to differentiate these lesions preoperatively. For this purpose, in this research, the value of fine-needle aspiration cytology (FNAC) in preoperative diagnosis was investigated by comparing with the postoperative histopathologic diagnosis.

Methods: One hundred aspirates from cystic lesions in the oral and maxillofacial region were included in this study. All of the samples except one were examined histopathologically and the results were compared.

Results: The results of the FNAC specimens obtained from 100 lesions were compared with histopathologic diagnosis of these lesions. According to these results, 12 insufficient (12\%), 7 positive (7\%), 81 negative (81\%) specimens were obtained. Among these 88 lesions, 69 of them were diagnosed specifically by cytological examination (78.4\%). 62 of the 69 specific diagnoses achieved by cytological examination were confirmed histopathologically (89.85\%). The histological types of the seven lesions were missed by cytological examination. There were not any complications related with the fineneedle aspiration procedure in the research.

Conclusions: According to these results, the value of fine-needle aspiration biopsy in cystic lesions of the maxillofacial region is found as successful as in the solid lesions. (Eur J Dent 2010;4:1-5)

Key words: Aspiration biopsy; Cystic; Fine-needle; Oral; Maxillofacial; Preoperative.

- a Associated Professor, Department of Oral and Maxillofacial Surgery, Faculty of Dentistry, Suleyman Demirel University, Isparta, Turkey. Professor, Department of Oral and Maxillofacial Surgery, Faculty of Dentistry, Ankara University, Ankara, Turkey.

Professor, Department of Pathology, Gülhane Military Medical Academy, Ankara, Turkey.

- Corresponding author: Dr. Timucin Baykul Istiklal Mahallesi 1101.sokak No:26/6 Isparta, Turkey. Phone: +90 2462113266 Fax: +90 2462370607

E-mail: timucinbaykuldyahoo.com

\section{INTRODUCTION}

Many of the bone lesions in the oral and maxillofacial region are cystic or have features similar to cystic lesions. These are odontogenic or nonodontogenic cysts, tumours and tumour-like lesions. Spectrum of the lesions having cyst-like radiolucency in the oral and maxillofacial region include; benign odontogenic cysts, aggressive cysts like keratocyst, calcifying odontogenic cyst, cystic tumours such as cystic ameloblastoma and other radiolucent non-odontogenic lesions. There 
are a large group of lesions that does not show any specific clinical and radiographical finding. ${ }^{1}$ Diagnosis of these intraosseous lesions is often problematic because of their proximity to tooth apices and neurovascular bundles and open biopsy is sometimes difficult. 2,3 Preoperative diagnosis is important for these lesions to achieve the optimal treatment planning. Fine-needle aspiration cytology (FNAC) may be used, as an alternative technique to open biopsy for preoperative diagnosis but the diagnostic value is not known completely in cystic lesions in the oral and maxillofacial region. ${ }^{4,5}$ The aspirates taken from cystic lesions have more material quantitatively but they are cellularly poor that makes the diagnosis difficult with FNAC. 5,6 The aim of this study was to detect the value of FNAC in the preoperative diagnosis of cystic lesions in the oral and maxillofacial region comparing with the histopathologic results.

\section{MATERIALS AND METHODS}

One hundred aspirates from cystic lesions in the oral and maxillofacial region were included in this study. The aspirations were made by 22-gauge needle and the majority of them were done by the same author (T.B.). In most of the intraosseous lesions, needle easily passed the bone because of thinning of the cortex. In a few cases, more effort was needed. Usually local anesthesia was not used during aspiration. Smears were prepared immediately after the aspiration and fixed with 90\% alcohol while wet. The smears were stained with haematoxylin-eosin or Papanicolou stains. The cytological diagnoses were divided into three groups; malignant, benign and insufficient for diagnosis. Malign and benign lesions also appraised to find out the histological types by cytological examination. All of the samples except one were examined histopathologically and the results were compared.

\section{RESULTS}

In this study, 81 benign (81\%) and 7 malignant lesions were diagnosed cytologically. The remaining 12 specimens were insufficient. There were 4 false negative results (5.79\%). Cytological diagnosis was 'chronic (lymphocyte rich) inflammation' in one of the false negatives, but histopathologic examination revealed a high-grade lymphoma. The cytological diagnoses of the other three false negatives were Warthin's tumour, ameloblastoma and benign cystic lesion, but histopathologic examination revealed that all of them were mucoepidermoid carcinoma. There were not any false positive results. Specific diagnoses were achieved in 69 of these 88 lesions (78.4\%) by cytological examination. Cytological and histopathologic diagnoses were similar in 62 specimens (89.85\%). Seven of the cytological specific diagnoses were not confirmed histopathologically including 4 false negative results. The other three were true negatives but histopathologic typing of the lesions were missed. Three of the cytologically insufficient cases were confirmed as osteosarcoma by histopathologic examination. The rest of the insufficient cases were benign intraosseous lesions. The specific diagnoses were shown in Table 1.

In this study, specificity was $95.06 \%$, sensitivity $100 \%$, accuracy $95.45 \%$, positive predictive value $100 \%$ and negative predictive value $95.06 \%$. There was not any complication related with the procedure.

\section{DISCUSSION}

FNAC is particularly helpful in the diagnosis of clinically non-characteristic lesions and has practically no contraindication. It is known as a usefull techinigue for the diagnosis of the head and neck masses but the use of this technique for the diagnosis of cystic lesions of oral and maxillofacial region is not widely accepted and there are a few studies on this subject. ${ }^{1,6-8}$ The first aim of FNAC is to detect if the lesion is malignant or benign. At the same time, it is possible to diagnose the lesions specifically by examining their cellular properties on the cytological specimen. ${ }^{9}$ In the present study, 69 of the sufficient 88 aspirates obtained from the cystic lesions were specifically diagnosed and 62 of them proved histopathologically. The correlation between cytological and histopathologic diagnosis was $89.85 \%$.

The FNAC can provide a simple and safer alternative to open biopsy with a low morbidity rate. The technique does not require much equipment. It is a non-traumatic and a cost-effective procedure. In the present study, there were not any complications related with FNAC. FNAC materials also permit the supplementary studies such as immunohistochemistry, electron microscopy, morphometric studies for diagnosis of specific 
typing of lesions. ${ }^{6,10,11}$ As information on the biological behaviour of a lesion in the preoperative period is very important, FNAC is a good starting point for the diagnosis and may clarify the next step as a minimally invasive procedure. ${ }^{12}$ In the present research, some lesions that resemble an odontogenic cyst radiographically were diagnosed as central giant cell granuloma, myxoma or cystic ameloblastoma by FNAC (Figures 1 and 2). In another case, a very specific Burkett lymphoma was diagnosed by FNAC without open biopsy. At the same time, malignancy was detected in 7 cases and there was not any false positive result. All of these cases showed that, maintaining the preoperative diagnosis will qualify the prognosis.

Aspirates of cystic bone lesions yield more material than firm lesions do. However, it is reported that, the diagnosis of aspirates from cystic lesions may be less specific than the FNAC diagnosis of solid lesions due to the paucity of specific lesional cells in the former. ${ }^{5,12} \mathrm{~A}$ diagnosis of 'benign cys- tic lesion' is justified in many instances. Ramzy et $\mathrm{al}^{13}$ reported that cysts of the jawbones may pose a problem in the differential diagnosis and exact location, history and radiological appearances must be considered before definitive cytological diagnosis is made. Lindberg and Akerman ${ }^{12}$ stated that the cystic character of the aspirate increases the number of false negatives in the salivary gland lesions. Dejmek and Lindholm ${ }^{5}$ suggested that non-diagnostic samples in their series were fewer among cystic lesions in contrast to the often-expressed diagnostic difficulties associated with them. August et $\mathrm{al}^{2}$ reported FNAC as a useful technique for intraosseous jaw lesions in their retrospective review of 32 specimens. The results of the present study showed that the diagnosis of cystic lesions of the head and neck in general is not less accurate (accuracy rate; $95.45 \%$ ) than of solid lesions in the same area.

Two factors that decrease the success of this technique is false negative and false positive re-

Table 1. The results of the cytologic and histopathologic comparison for the lesions diagnosed specifically.

\begin{tabular}{|c|c|c|c|c|c|}
\hline Histopath. Diagnosis & $\mathrm{N}$ & Negative & Positive & Insufficient & Specific Diagnosis \\
\hline Odontogenic Cyst & 50 & 48 & & 2 & 39 \\
\hline Giant Cell Granulo. & 9 & & & & 9 \\
\hline Pleomorphic Adeno. & 3 & 1 & & & 2 \\
\hline Ameloblastoma & 2 & & & & 2 \\
\hline Squamous Cell Ca & 2 & & & & 2 \\
\hline Adenoid Cystic $\mathrm{Ca}$ & 2 & & & & 2 \\
\hline Mucoepidermoid Ca & 4 & 3 & & & 1 \\
\hline Malign Melanoma & 1 & & & & 1 \\
\hline Inflammatorygranu Tissue & 6 & 3 & & 2 & 1 \\
\hline Odontogenic Myxom & 1 & & & & 1 \\
\hline Histiositozis & 1 & & & & 1 \\
\hline Osteomyelit & 1 & & & & 1 \\
\hline Lymphoma & 2 & & & 1 & 1 \\
\hline Ossifi. Fibrom & 2 & 2 & & & \\
\hline Squamous Odontoge. Tum. & 1 & 1 & & & \\
\hline Hemangiomoa & 1 & 1 & & & \\
\hline Fibrous Dysplasia & 1 & & & 1 & \\
\hline Hyper Keratosis & 1 & & & 1 & \\
\hline Schwannoma & 1 & & & 1 & \\
\hline Malignant Tum. & 1 & & & 1 & \\
\hline Cytic Ameloblastoma & 5 & 3 & & 2 & \\
\hline
\end{tabular}


sults. The increase in false negative results is related to the aspirations performed from small lesions and presence of secondary infections during aspiration. False negativity may also be due to sampling errors, haemorrhage, excessive fibrosis or necrosis. Negative reports do not eliminate the clinical possibility of malignancy. False negativity was reported between $1.2-10 \%$ in the related studies. In this study, there were 4 false negative results (5.79\%) Cytological diagnosis was 'chronic (lymphocyte rich) inflammation' in one of the false negatives, but histopathologic examination re-

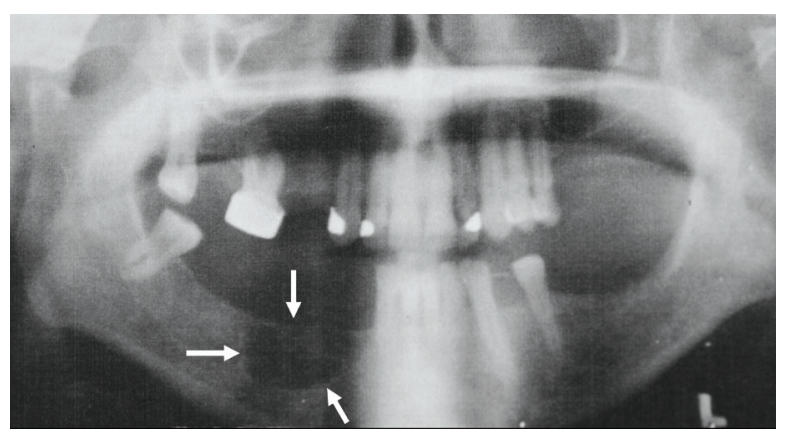

Figure 1. Radiological appearance of a lesion seems like a residuel cyst, but fine needle aspiration cytology showed that it was a giant cell granuloma.

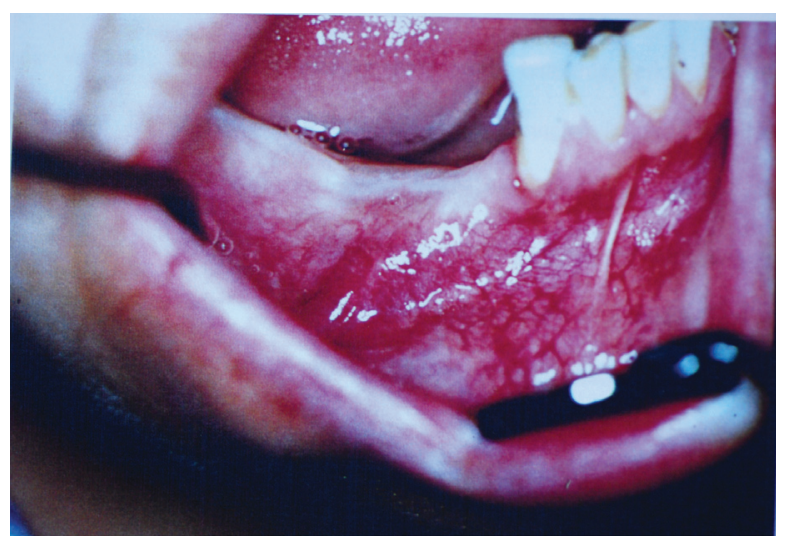

Figure 2. Clinical appearance of the same lesion. The overlying mucosa was normal and there was not any sign or symptom.

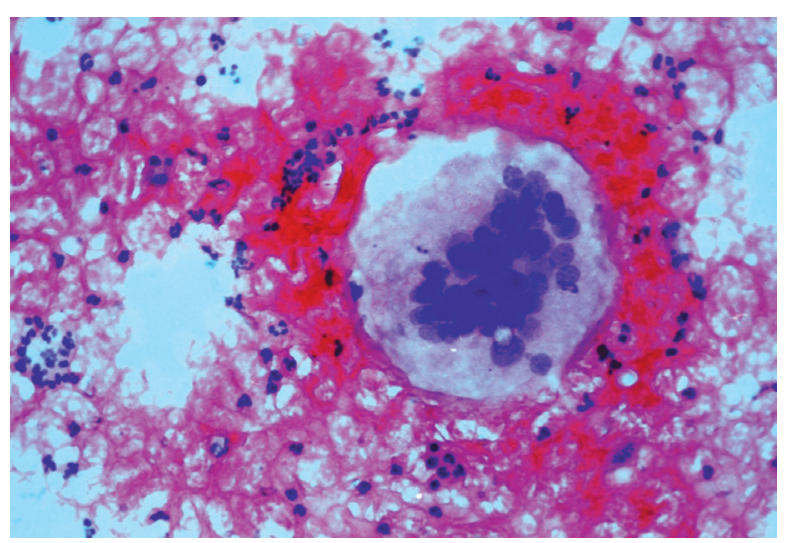

Figure 3. Cytologic appearance of the central giant cell granuloma diagnosed with FNAB. vealed a high-grade lymphoma. The cytological diagnosis of the other three false negatives was Warthin's tumour, ameloblastoma and benign cystic lesion, but histopathologic examination revealed that all of them were mucoepidermoid carcinoma. These three lesions were intraoseous lesions. Fewer amounts of atypia and mitosis in mucoepidermoid carcinoma and less amount of lesional cells resulted with false negative results. The presence of poor cellular material with fewer amounts of lesional cells may lead false negative results. This also depends on the criteria of sufficiency. There are not yet any accepted criteria for sufficiency. Mainly six well-protected cluster was accepted sufficient in this study. But the false negative results showed that this criterion is not suitable for some lesions. The most important factors for false positive results are the absence of clinicopathological correlation and lack of experience of the pathologist.6,14 The clinician's manner after the cytological diagnosis may also influence the decision of the pathologist. Increased experience of both the pathologist and the surgeon and a team working that detects the clinical and radiographic findings alltogether should be necessary for successful results. False positivity was reported between $0-2 \%$ in the studies related to the head and neck region ${ }^{15}$ and there was not any false positive in our study.

\section{CONCLUSIONS}

Fine needle aspiration cytology is a technique that was proved as easy, non-traumatic, economic, safe and reliable especially in differentiation of benign and malignant lesions in the oral and maxillofacial region. According to the results of this study, FNAC of cystic lesions in the maxillofacial region may be useful for preoperative diagnosis as in solid lesions.

\section{REFERENCES}

1. Guyot J, Obradovic D, Kroyenbuhl M, Zbaeren P, Lehman W. Fine-needle aspiration in the diagnosis of head and neck growth. Is it necessary? Otolaryngol Head Neck Surg 1990;103:697-701.

2. August M, Faquin CW, Ferraro N, Kaban L. Fine-needle aspiration biopsy of intraosseous lesions. J Oral Maxillofac Surg 1999;57:1282-1286. 
3. Vargas PA, Prado FO, Fregnani ER. Fine needle aspiration biopsy in central giant cell lesion. A report of 3 cases. Acta Cytol 2006;50:449-454.

4. Barnard N, Paterson W, Irvine H, Mackenzie F, White H. Fine-needle aspiration cytology in maxillo-facial surgery: Experience in a district general hospital. Br J Oral Maxillofac Surg 1993;31:223-226.

5. Dejmek A, Lindholm K. Fine-needle aspiration biopsy of cystic lesions of head and neck, excluding the thyroid. Acta Cytol 1990;34:443-448.

6. Günhan Ö, Doğan N, Celasun B, Sengün O, Önder T, Finci R. Fine-needle aspiration cytology of oral cavity and jaw bone lesions. A report of 102 cases. Acta Cytol 1993;37:135-141.

7. Ramzy I, Aufdemorte TB, Duncan DL. Diagnosis of radiolucent lesions of the jaw by fine needle aspiration biopsy. Acta Cytol 1993;29:419-424.

8. Weymuller E, Kiviat N, Duckert L. Aspiration cytology: An efficient and cost-effective modality. Laryngoscope 1983;93:561-564

9. Platt J, Davidson D, Nelson C, Weisberger W. Fine-needle aspiration biopsy. An analysis of 89 head and neck cases. $J$ Oral Maxillofac Surg 1990;48:702-706.

10. Günhan Ö. Fine-needle aspiration cytology of ameloblastoma. Acta Cytol 1996;40:967-969.

11. Vargas PA, da Curuz Perez DE, Mata GM, de Almeida OP, Jones AV, Gerhard R. Fine needle aspiration cytology as an additional tool in the diagnosis of odontogenic keratocyst. Cytopathology 2007;18:361-366.

12. Mc Lean NR, Griffiths K, Shaw J, Trott P. Fine-needle aspiration cytology in the head and neck region. Br J Plas Surg 1998;42:449-451

13. Platt B, Schaefer S, Vvitch F. Role of fine-needle aspiration in the evaluation of neck masses. Med Clin North Am 1993;77:611-623.

14. Shinoda T, Iwarta H. Cytologic appearence of carcinoma (malignant ameloblastoma and fibrosarcoma) of the maxilla. A case report. Acta Cytol 1992;36:131-136.

15. Stormby N, Akerman M. Cytodiagnosis of bone lesions by means of fine-needle aspiration biopsy. Acta Cytol 1973;17:166-173. 